\title{
NOTATIONAL, SEQUENTIAL, AND T-PATTERNS ANALYSIS OF THE TACTICAL SCHEMES OF A PROFESSIONAL FUTSAL TEAM
}

original paper

( ) University School of Physical Education in Wroclaw

DOI: https://doi.org/10.5114/hm.2018.79737

\section{ANTONIO FERREIRA ${ }^{1}$, RUI SANTOS ${ }^{1}$, HUGO LOURO ${ }^{2}$, PAULO MALICO SOUSA ${ }^{1}$, VALTER PINHEIRO ${ }^{1}$, FERNANDO SANTOS ${ }^{3}$}

${ }^{1}$ Instituto Superior de Ciências Educativas, Lisbon, Portugal

${ }^{2}$ Polytechnic Institute of Santarém, School of Sports of Rio Maior, Rio Maior, Portugal

${ }^{3}$ Polytechnic Institute of Setúbal, Setúbal College of Education, Setúbal, Portugal

\section{ABSTRACT}

Purpose. The present study intends to analyse the tactical schematics, outs, and corners marked in the last 12 meters of the court, through notational analysis, sequential analysis, and detection of T-patterns.

Methods. We analysed outs $(n=71)$ and corners $(n=46)$ performed by the professional futsal team of Sport Lisbon and Benfica. The Tactical Scheme Observation System in Futsal and the Lince ${ }^{\circledR}$ computer program were used. The data were analysed with IBM SPSS Statistics ${ }^{\circledR}$, SDIS-GSEQ $^{\circledR}$, and THEME ${ }^{\circledR}$ programs.

Results. The finalization of the tactical schemes takes place preferably after a pass, to the outer zones 5 , 8 , and 9 . The sequential analysis showed some regularities when there is a second pass directed to zones 5 and 6 , and regularity was verified in the finalization in interior zone 2. T-patterns were recorded in the execution of the observed tactical schemes.

Conclusions. The finalization of the tactical schemes takes place after 1 or 2 passes occurring in external areas.

Key words: futsal, observation and analysis, observational methodology, tactical schemes

\section{Introduction}

In today's sport, observation and analysis have a great relevance since they contribute to the development of athletes and teams and help coaches and athletes to make decisions [1]. This relevance is verified during the training microcycle, notably in the adjustment of the training exercises, in the adequacy of the coach's intervention in the meetings with the team and in the training process $[2,3]$. The coach can manipulate different constraints of the training exercises in order to potentiate decision-making behaviours desired for the players and team [4]. In futsal, observation and analysis are critical to understand what is happening in the game, to identify errors and positive aspects of the team, and to analyse the opponent's game strategy $[2,5]$.
Futsal is an invasion sport, where there is a permanent confrontation between attack and defence, where they establish relations of cooperation vs. opposition, characterized by great unpredictability and randomness [6-8]. It is through a collective positional organization that teams seek to create advantageous situations to finalize and achieve the goal [9]. The characteristics of the playing court and the futsal regulation make the technical-tactical aspects essential [10, 11]; the lack of space and time forces players to move, to think, and to make decisions quickly so that they can anticipate events, create spaces and opportunities for goals [12]. In futsal, one of the important conditions for creating and implementing finalization actions are tactical schemes. Through organized and trained movements, the team creates favourable circumstances for achieving the goal [6]. According to Santos and Nav-

Correspondence address: Fernando Jorge Lourenço dos Santos, Department of Science and Technology, Instituto Politécnico de Setúbal - Escola Superior de Educação, Campus do Instituto Politécnico de Setúbal, Estefanilha, 2914-504 Setúbal, Portugal, e-mail: fjlsantos@gmail.com

Received: September 26, 2018

Accepted for publication: November 14, 2018

Citation: Ferreira A, Santos R, Louro H, Sousa PM, Pinheiro V, Santos F. Notational, sequential, and T-patterns analysis of the tactical schemes of a professional futsal team. Hum Mov. 2018;19(5)special/issue:29-39; doi: https://doi.org/10.5114/ hm.2018.79737. 
A. Ferreira, R. Santos, H. Louro, P. M. Sousa, V. Pinheiro, F. Santos, Tactical scheme analysis in futsal

arro [13], in the attack vs. defence situations, characteristic of the game of futsal, sometimes owing to strong marking, the ability to close spaces by the opponent, tactical schemes arise as a strategy that can surprise the opponent and change the result of the game. Several studies have pointed to this importance of tactical schemes for achieving the goal $[6,10,13,14]$.

Nevertheless, our study does not intend to constitute a mere notational analysis of goals obtained through tactical schemes; our purpose is to get to know a little more about this moment of great importance in the futsal game. Through observation and analysis, we are going to investigate the marking zones of tactical schemes, the zones of the first and second pass, as well as the preference zones of finalization. Accordingly, our aim is to examine the way the observed team performs tactical schemes, as well as to verify the existence of behavioural patterns [15-17], using the accomplishments of different analytical techniques [18].

\section{Material and methods}

To develop these studies, we applied the observational methodology, a scientific procedure which, with the consideration of defined objectives, allows to code perceptual behaviours with a specifically constructed instrument $[19,20]$. This methodology enables organized registration and quantification of game actions in the natural context [21], which favours ecological validity [22], as the game is studied in its usual dynamics. The observational design of the research is ideographic (study of a team), sequential - involves follow-up (along the journeys of the futsal league), multidimensional (various dimensions studied of the tactical diagrams), and intensive (data of behaviour sequences) (I/S/M/I, ideographic, sequential, multidimensional, intensive) [23].

\section{Sample}

The observational sample consisted of corners $(n=$ $46)$ and outs $(n=71)$ performed by the professional futsal team of Sport Lisbon and Benfica in the Sportzone league in 2016-2017. The videos observed were related to the games of the $14^{\text {th }}-26^{\text {th }}$ journeys. Only the tactical schemes that were implemented in the last 12 meters of the futsal court were examined, and the direction of the attack of the observed team was considered.

\section{Instrument}

The observational instrument used is a system of categories that was built specifically for the study of the tactical schemes of futsal - Tactical Scheme Observation System in Futsal (TSOSF) [23]. The instrument was built on the basis of a revision of the literature, and the actions relating to the tactical schemes were developed in conjunction with a professional futsal team and later subjected to a validation process by $\mathrm{PhD}$ experts and research conducted under the observational methodology $[8,24]$. The suggested amendments were made and the final version of TSOSF (Table 1) was drawn up.

In the context of the observational methodology, the analysis of reliability is a fundamental issue, with a view to the quality of the data [25]. The training of observers and the analysis of reliability considered the procedures suggested by Brewer and Jones [26]. The values for the inter-observer and intra-observer reliability were obtained through the agreement measure of Cohen's kappa [27] with the use of the Lince ${ }^{\circledR}$ program to calculate the values referred to on average and for all the criteria [28]. We obtained inter-observer and intra-observer reliability values for all criteria and on average over 0.90 .

\section{Procedures}

The videos of the games were obtained through the Portuguese Football Federation (http://www.fpf.pt/pt/ competicoes/futsal/masculino/liga-sportzone), and later analysis was made of these and selected the game situations related to corners and outsides. The final video with the tactical schemes to be observed was carried out with the Windows Movie Maker ${ }^{\circledR}$ computer program. To perform the coding of the observed tactical schemes, the Lince ${ }^{\circledast}$ computer program was used [29], software that allows to export data to the Microsoft Excel $^{\circledR}$ program, which in turn enables their use in IBM SPSS Statistics $^{\circledast}$, SDIS-GSEQ ${ }^{\circledast}[30]$, and THEME $^{\circledast}[31]$.

\section{Data analysis}

The processing of the collected data was carried out through the descriptive statistics (frequency and percentage) with the use of the IBM SPSS Statistics ${ }^{\circledR}$ computer program.

In view of the observational design of our investigation, the data analysis could be performed through the sequential analysis and detection of T-patterns [23].

Sequential analysis allows to determine patterns of conduct or stable transitions that are above odds marked by chance [32]. With the sequential analysis, by the technique of retards, it is possible to assess the possibility of correlation between behaviours, with the 
Table 1. Tactical Scheme Observation System in Futsal (TSOSF)

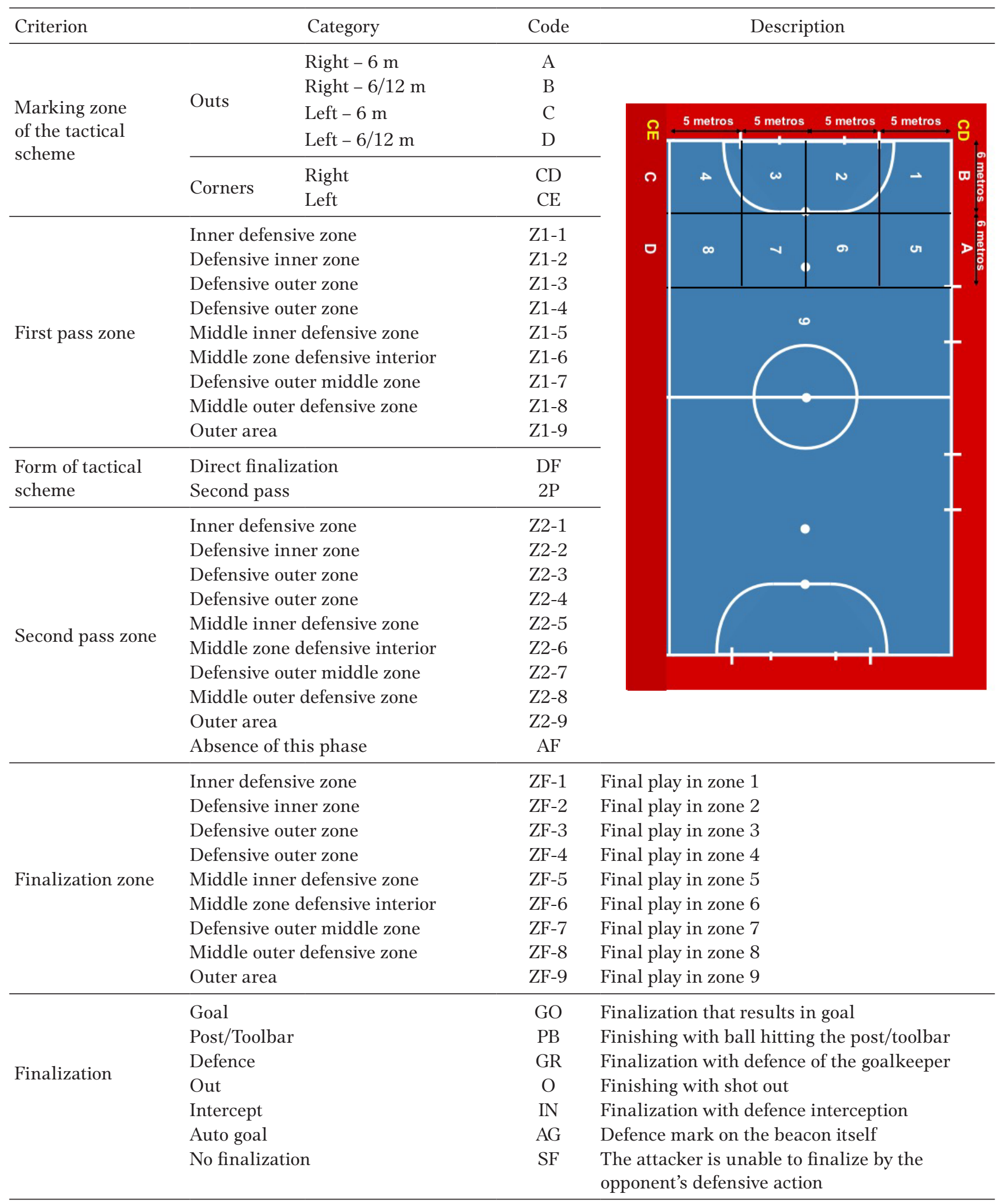


A. Ferreira, R. Santos, H. Louro, P. M. Sousa, V. Pinheiro, F. Santos, Tactical scheme analysis in futsal

behaviour criterion [33], and this can be carried out in a prospective or retrospective way [32]. With the adjusted residue analysis $(Z \geq 1.96)$, it is possible to check the occurrence of behaviours depending on the previous occurrence of others [33-35]. To perform sequential analysis, we used the SDIS-GSEQ ${ }^{\circledast}$ computer program [30]. There were correlations between the different conducts: finishing zone $(-1)$, second pass zone $(-2)$, form of the tactical scheme (-3), zone of the first pass $(-4)$, and zone of marking of the tactical scheme (-5), with the criterion (finalization) of a retrospective. In this way, and taking into account the $Z$ value, we could check standard sequences or simply some regularities.

Regarding the detection of T-patterns, we used the THEME $^{\circledR}$ program, which analyses and detects temporal and sequential structures of a series of data [31]. The algorithm for detection of T-patterns consists of a series of routines for detecting critical intervals, pattern building, and competition of complete patterns [36]. The detection of the critical intervals between behaviours is in the centre of the detection of T-patterns [37]. The algorithm also allows redundant detection of partial and equivalent T-patterns to be eliminated [36]. For the detection of T-patterns, the following criteria were defined: minimum frequency of occurrence of $3(n=3)$ and the level of significance of $p<0.001$. The program generates hierarchical relationships, and only T-patterns are selected which have coherence regarding the sequence of behaviours defined in the instrument. The number of occurrences where a T-pattern is recorded in full and in part is also graphically displayed.

\section{Ethical approval}

The conducted research is not related to either human or animal use.

\section{Results}

The results presented below are related to the analysis of the tactical schemes of the professional futsal team of Sport Lisbon and Benfica. First, the results of the notational analysis are presented (Table 2), followed by the results of the sequential analysis (Tables 3 and 4) and detection of T-patterns (Figures 1-5).

Through the sequential analysis of the tactical schemes - out (Table 3), we did not check pattern sequences for these specific parts of the futsal game. However, we found some regularities in the way advantageous situations were created to finish, notably in the outside marking zone (zone A - at 6 meters in the right corridor), in the first passes to zones 3 and 8 , in the second passes effected for zones 5 and 6 , as well as in the finales performed in zone 2 .

Also, in Table 4, we can check some regularities in the way the observed team marked the corners, notably in the implementation of the first passes for zones 3 and 8 , of the second passes for zones 2 and 6 , and in the finalization in zone 2 .

Figure 1 presents a pattern in the execution of the tactical scheme outside; the ball is passed to the opposite corridor to appear in the finalization. The total occurrence was verified as 6 times $(n=6)$.

Figure 2 illustrates one of the patterns that happen more frequently in the execution of the outsides $(n=8)$. The same T-patterns were also recorded when the outsides were marked in zones A $(n=4), \mathrm{C}(n=$ $4)$, and D $(n=6)$. Accordingly, the identical patterns, in which the tactical scheme was marked for finalization zone 9 , were recorded 22 times $(n=22)$.

The T-pattern depicted in Figure 3 demonstrates another method of marking the outsides, promoting the finalization with the execution zone of the tactical scheme, after a short pass $(n=5)$. We recorded an identical pattern when the outside was marked in zone $\mathrm{D}$ and finalization in zone $8(n=4)$.

Figure 4 shows a T-pattern verified in the marking of corners, where the finalization took place after the first pass to zone $9(n=5)$.

In Figure 5, a T-pattern can be observed in which the movement of players freed a player in zone 7 for finalization $(n=3)$.

\section{Discussion}

The objective of our study focused on tactical schemes (outsides and corners) marked in the last 12 meters, of a senior male futsal team of Sport Lisbon and Benfica. For these, we performed a notational analysis, which allowed to make a statistical compilation [38] of the actions ranging from the marking zone of the outsides and corners to the finalization zone, enabling identification of performance indicators [39]. One of the issues referred to by futsal coaches as important in the observation and analysis of a game is the detection of game patterns [2]. Through the sequential analysis and the detection of T-patterns, it was possible to obtain pattern sequences related to tactical schemes [40], moments of special importance since they can surprise the opponent and change the outcome of the game $[1,13]$. We managed to find, through the sequential analysis carried out with SDIS-GSEQ ${ }^{\circledR}$, some regularities regarding this specific moment of the game; 
Table 2. Notational analysis of tactical schemes

\begin{tabular}{|c|c|c|c|c|c|c|c|}
\hline \multirow{2}{*}{ Criterion } & \multirow{2}{*}{ Categories } & \multicolumn{2}{|c|}{ Outs } & \multicolumn{2}{|c|}{ Corners } & \multicolumn{2}{|c|}{ Total } \\
\hline & & Sum & $\%$ & Sum & $\%$ & Sum & $\%$ \\
\hline \multirow{6}{*}{$\begin{array}{l}\text { Marking zone } \\
\text { of the tactical scheme }\end{array}$} & Right corner & - & - & 28 & $60.87 \%$ & 28 & $23.93 \%$ \\
\hline & Left corner & - & - & 18 & $39.13 \%$ & 18 & $15.38 \%$ \\
\hline & Out right $6 \mathrm{~m}$ & 12 & $16.90 \%$ & - & - & 12 & $10.26 \%$ \\
\hline & Out right 6-12 m & 19 & $26.76 \%$ & - & - & 19 & $16.24 \%$ \\
\hline & Out left $6 \mathrm{~m}$ & 10 & $14.08 \%$ & - & - & 10 & $8.55 \%$ \\
\hline & Out left 6-12 m & 30 & $42.25 \%$ & - & - & 30 & $25.64 \%$ \\
\hline \multirow{9}{*}{ First pass zone } & $\mathrm{Z1-1}$ & 2 & $2.82 \%$ & 0 & $0 \%$ & 2 & $1.71 \%$ \\
\hline & $\mathrm{Z1-2}$ & 1 & $1.41 \%$ & 6 & $13.04 \%$ & 7 & $5.98 \%$ \\
\hline & $\mathrm{Z1-3}$ & 3 & $4.23 \%$ & 2 & $4.35 \%$ & 5 & $4.27 \%$ \\
\hline & $\mathrm{Z1-4}$ & 2 & $2.82 \%$ & 1 & $2.17 \%$ & 3 & $2.56 \%$ \\
\hline & $\mathrm{Z1-5}$ & 20 & $28.17 \%$ & 3 & $6.52 \%$ & 23 & $19.66 \%$ \\
\hline & $\mathrm{Z1-6}$ & 3 & $4.23 \%$ & 5 & $10.87 \%$ & 8 & $6.84 \%$ \\
\hline & $\mathrm{Z1-7}$ & 7 & $9.86 \%$ & 6 & $13.04 \%$ & 13 & $11.11 \%$ \\
\hline & $\mathrm{Z1-8}$ & 12 & $16.90 \%$ & 6 & $13.04 \%$ & 18 & $15.38 \%$ \\
\hline & Z1-9 & 21 & $29.58 \%$ & 17 & $36.96 \%$ & 38 & $32.48 \%$ \\
\hline \multirow{2}{*}{ Form of tactical scheme } & Direct finalization & 59 & $83.10 \%$ & 44 & $95.65 \%$ & 103 & $88.03 \%$ \\
\hline & Second pass & 12 & $16.90 \%$ & 2 & $4.35 \%$ & 14 & $11.97 \%$ \\
\hline \multirow{10}{*}{ Second pass zone } & $\mathrm{Z} 2-1$ & 0 & $0 \%$ & 0 & $0 \%$ & 0 & $0 \%$ \\
\hline & $\mathrm{Z} 2-2$ & 4 & $5.63 \%$ & 0 & $0 \%$ & 4 & $3.42 \%$ \\
\hline & $\mathrm{Z} 2-3$ & 1 & $1.41 \%$ & 1 & $2.17 \%$ & 2 & $1.71 \%$ \\
\hline & $\mathrm{Z} 2-4$ & 0 & $0 \%$ & 1 & $2.17 \%$ & 1 & $0.85 \%$ \\
\hline & $\mathrm{Z} 2-5$ & 2 & $2.82 \%$ & 0 & $0 \%$ & 2 & $1.71 \%$ \\
\hline & $\mathrm{Z} 2-6$ & 1 & $1.41 \%$ & 0 & $0 \%$ & 1 & $0.85 \%$ \\
\hline & $\mathrm{Z} 2-7$ & 0 & $0 \%$ & 0 & $0 \%$ & 0 & $0 \%$ \\
\hline & $\mathrm{Z} 2-8$ & 3 & $4.23 \%$ & 0 & $0 \%$ & 3 & $2.56 \%$ \\
\hline & Z2-9 & 0 & $0 \%$ & 0 & $0 \%$ & 0 & $0 \%$ \\
\hline & Absence of this phase & 60 & $84.51 \%$ & 44 & $95.65 \%$ & 104 & $88.89 \%$ \\
\hline \multirow{9}{*}{ Finalization zone } & $\mathrm{ZF}-1$ & 0 & $0 \%$ & 0 & $0 \%$ & 0 & $0 \%$ \\
\hline & $\mathrm{ZF}-2$ & 3 & $4.41 \%$ & 6 & $13.04 \%$ & 9 & $7.89 \%$ \\
\hline & $\mathrm{ZF}-3$ & 3 & $4.41 \%$ & 2 & $4.35 \%$ & 5 & $4.39 \%$ \\
\hline & $\mathrm{ZF}-4$ & 1 & $1.47 \%$ & 1 & $2.17 \%$ & 2 & $1.75 \%$ \\
\hline & $\mathrm{ZF}-5$ & 20 & $29.41 \%$ & 3 & $6.52 \%$ & 23 & $20.18 \%$ \\
\hline & $\mathrm{ZF}-6$ & 1 & $1.47 \%$ & 5 & $10.87 \%$ & 6 & $5.26 \%$ \\
\hline & $\mathrm{ZF}-7$ & 7 & $10.29 \%$ & 6 & $13.04 \%$ & 13 & $11.40 \%$ \\
\hline & $\mathrm{ZF}-8$ & 13 & $19.12 \%$ & 6 & $13.04 \%$ & 19 & $16.67 \%$ \\
\hline & ZF-9 & 20 & $29.41 \%$ & 17 & $36.96 \%$ & 37 & $32.46 \%$ \\
\hline \multirow{7}{*}{ Finalization } & Goal & 3 & $4.23 \%$ & 0 & $0 \%$ & 3 & $2.56 \%$ \\
\hline & Post/Toolbar & 0 & $0 \%$ & 0 & $0 \%$ & 0 & $0 \%$ \\
\hline & Defence & 16 & $22.54 \%$ & 10 & $21.74 \%$ & 26 & $22.22 \%$ \\
\hline & Out & 25 & $35.21 \%$ & 17 & $36.96 \%$ & 42 & $35.90 \%$ \\
\hline & Intercept & 26 & $36.62 \%$ & 17 & $36.96 \%$ & 43 & $36.75 \%$ \\
\hline & Auto goal & 0 & $0 \%$ & 0 & $0 \%$ & 0 & $0 \%$ \\
\hline & No finalization & 1 & $1.41 \%$ & 2 & $4.35 \%$ & 3 & $2.56 \%$ \\
\hline
\end{tabular}

According to Table 1, we can verify that the finalization of the tactical schemes happens preferably after first pass to zones 5,8 , and 9 . We determined that the areas where more finishes occurred were 5,8 , and 9 . In the observed team, there was a low value of goals obtained in these specific game situations. The goals obtained resulted from tactical schemes - out. The finales were defended by a goalkeeper, exiting the end line, and were intercepted by the opponents' defences. 


\section{HUMAN MOVEMENT}

A. Ferreira, R. Santos, H. Louro, P. M. Sousa, V. Pinheiro, F. Santos, Tactical scheme analysis in futsal

Table 3. Sequential analysis of the outs

\begin{tabular}{|c|c|c|c|c|c|c|}
\hline $\mathrm{R}-5$ & $\mathrm{R}-4$ & $\mathrm{R}-3$ & $\mathrm{R}-2$ & R-1 & Conduct criterion & \\
\hline & Z1-3 (2.69)* & & & $\mathrm{Z} 2-5(2.75)$ & Goal & \\
\hline & & & & & Post/Toolbar & \\
\hline ZF-4 (2.03) & ZF-1 (2.05) & $\begin{array}{l}\text { Z1-7 (1.99) } \\
\text { Z2-5 (2.13)* } \\
\text { Z2-6 (2.06)* }\end{array}$ & ZF-4 (2.00) & $\mathrm{Z} 2-5(2.75)$ & Defence & \\
\hline \multirow[t]{3}{*}{$\mathrm{A}(2.02) *$} & & Z1-9 (2.28) & & & Out & \\
\hline & & ZF-8 (2.54) & $\begin{array}{l}\text { Z1-2 (1.99) } \\
\text { Z1-6 (2.85) } \\
\text { Z2-6 (1.99) } \\
\text { ZF-6 (2.64) }\end{array}$ & $\begin{array}{l}\mathrm{C}(2.26) \\
\mathrm{Z} 1-2(2.01) \\
\mathrm{ZF}-2(2.01)^{*}\end{array}$ & Intercept & : \\
\hline & $\begin{array}{l}\mathrm{Z} 1-8(2.34)^{*} \\
\mathrm{ZF}-4(8.77)\end{array}$ & & & & $\begin{array}{c}\text { Auto goal } \\
\text { No finalization }\end{array}$ & : \\
\hline
\end{tabular}

* Level of significance $Z \geq 1.96$

Table 4. Sequential analysis of the corners

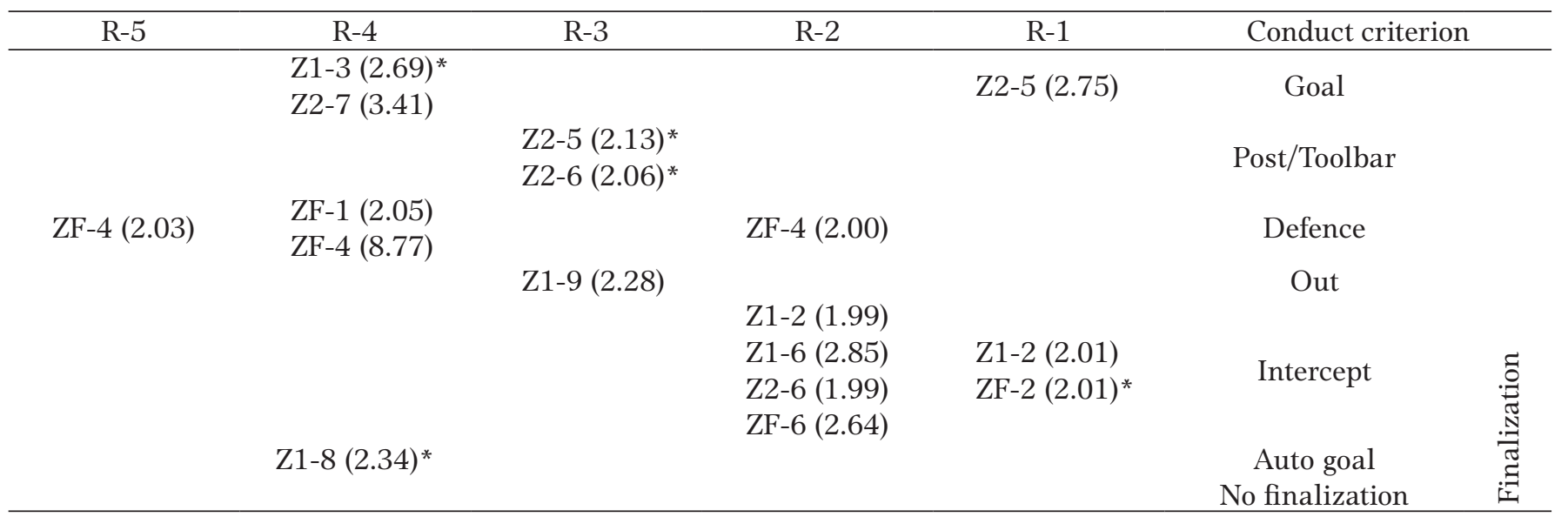

* Level of significance $Z \geq 1.96$

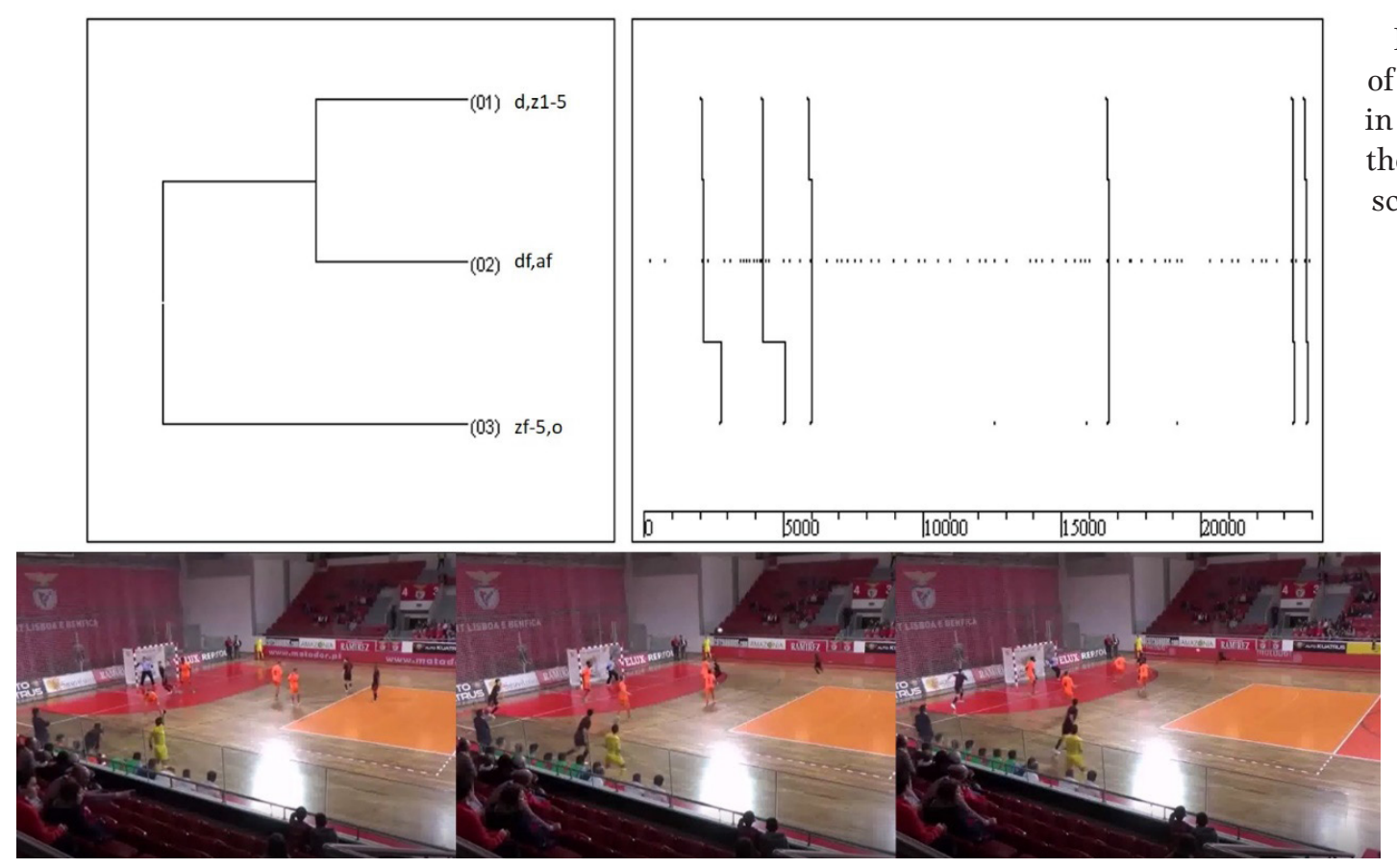

Figure 1. T-patterns of termination situation in zone 5 resulting from the execution of tactical scheme - out in zone D 
A. Ferreira, R. Santos, H. Louro, P. M. Sousa, V. Pinheiro, F. Santos, Tactical scheme analysis in futsal

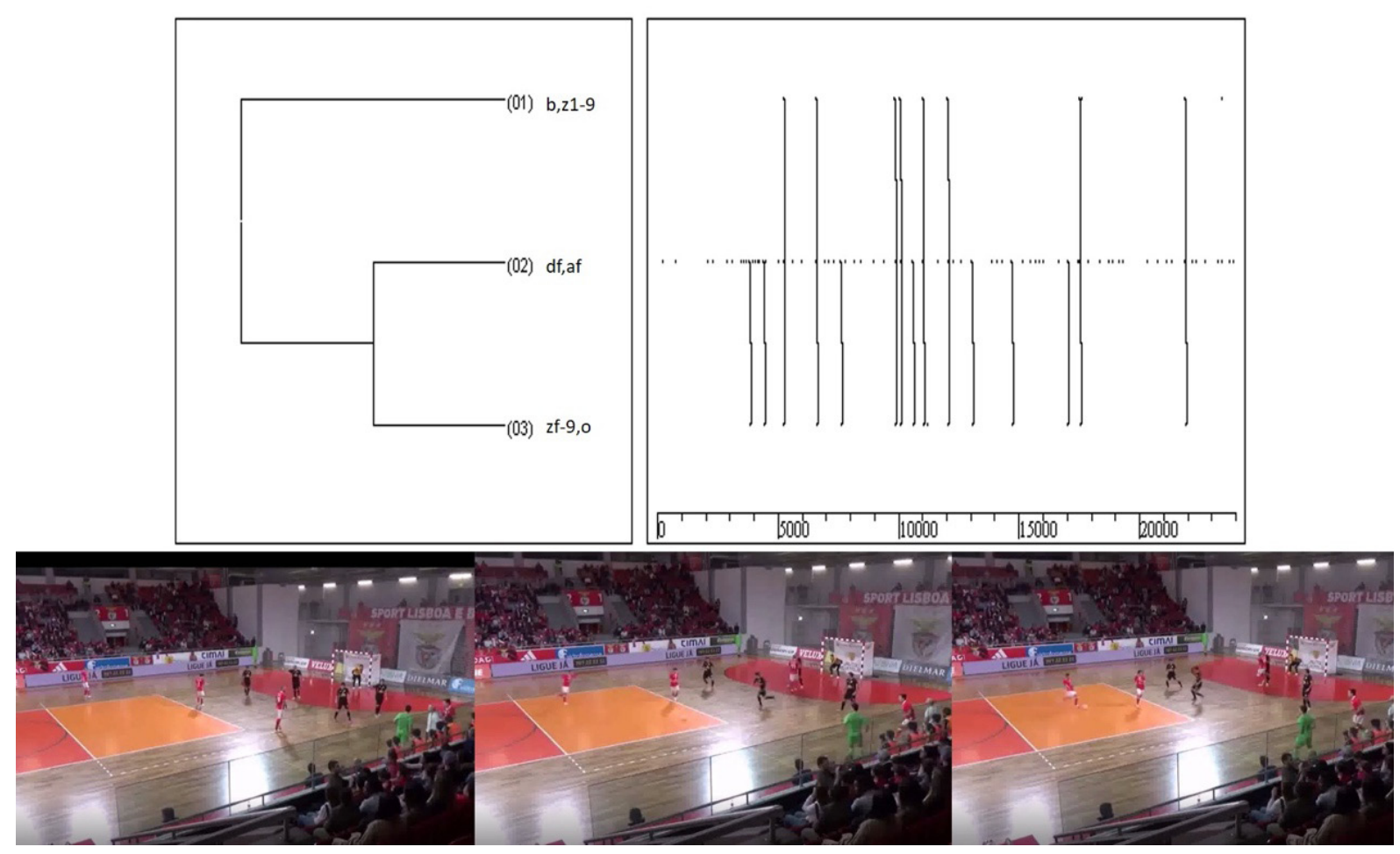

Figure 2. T-patterns of termination situation in zone 9 resulting from the execution of tactical scheme out in zone B

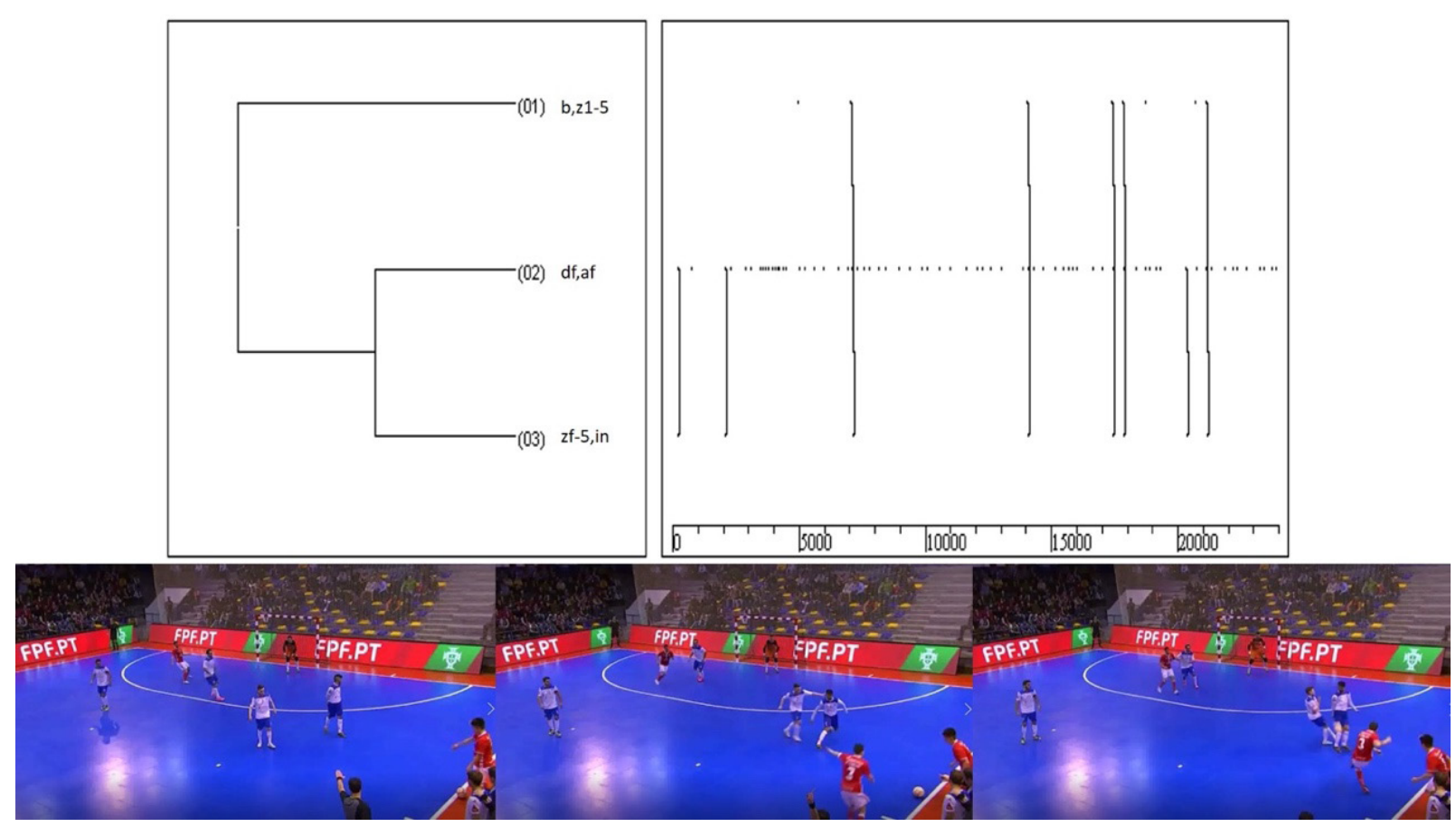

Figure 3. T-patterns of termination situation in zone 5 resulting from the execution of tactical scheme out in zone B 


\section{HUMAN MOVEMENT}

A. Ferreira, R. Santos, H. Louro, P. M. Sousa, V. Pinheiro, F. Santos, Tactical scheme analysis in futsal

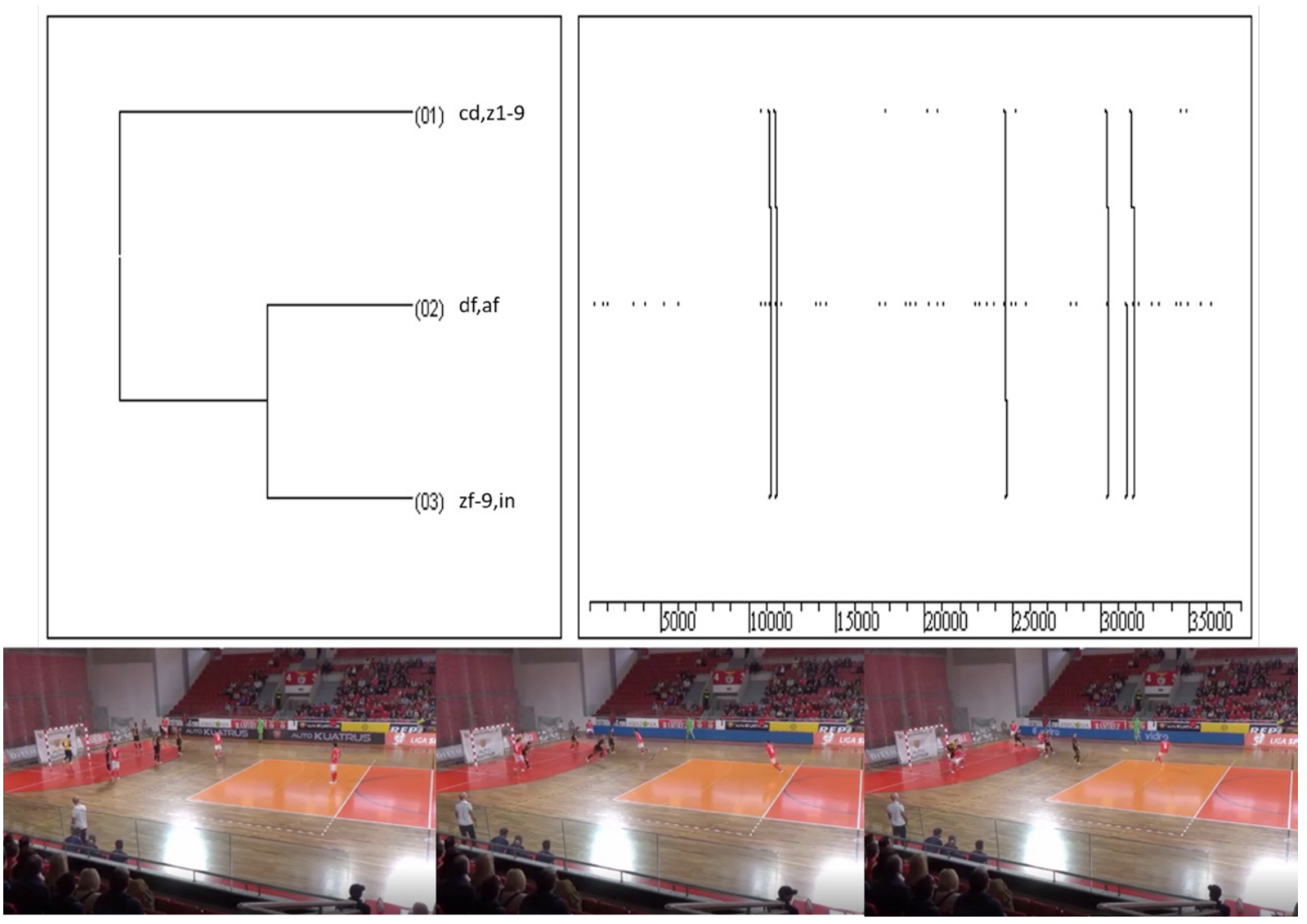

Figure 4. T-patterns of termination situation in zone 9 resulting from the execution of tactical scheme corner in zone $\mathrm{CD}$

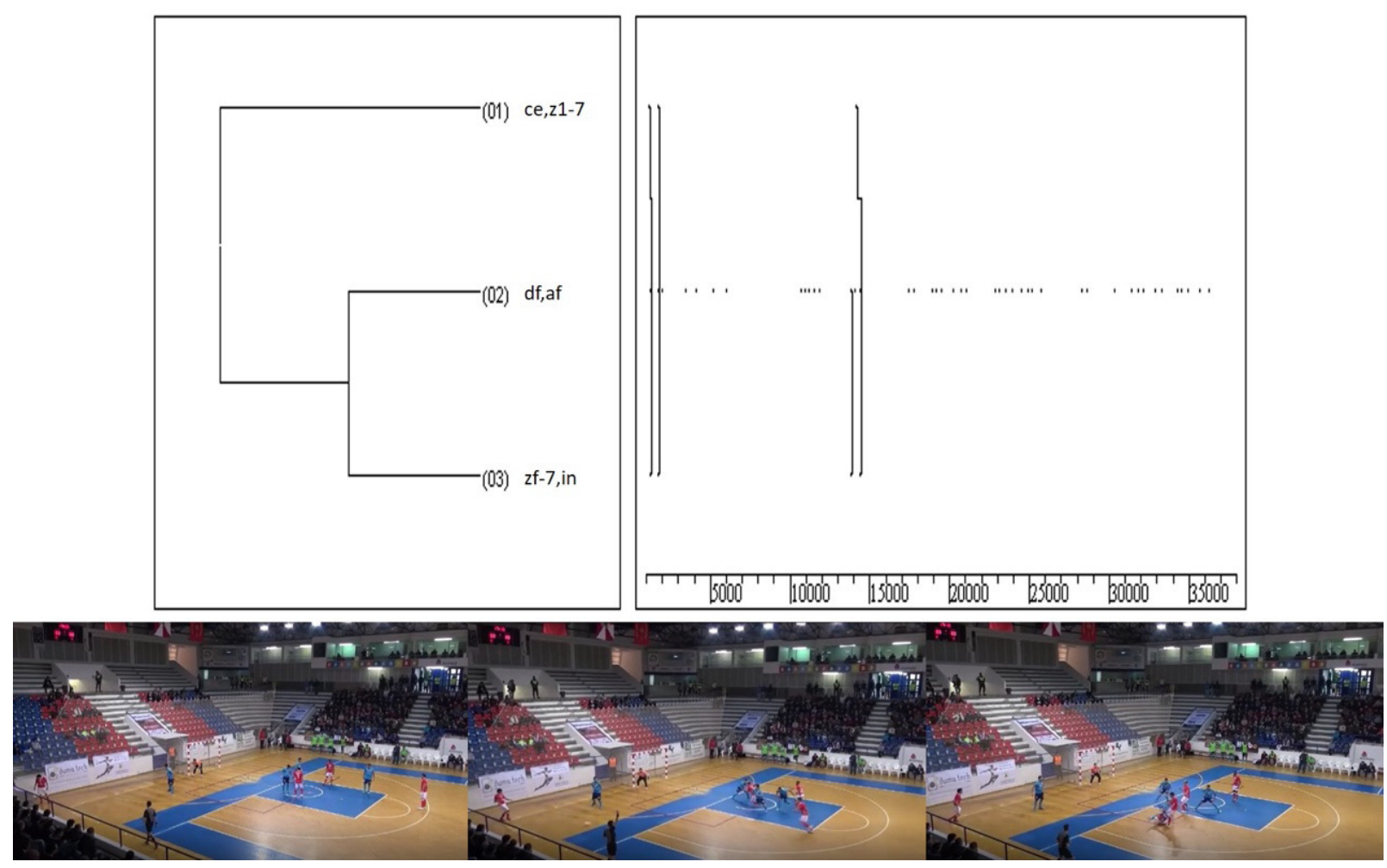

Figure 5. T-patterns of termination situation in zone 7 resulting from the execution of tactical scheme corner in zone $\mathrm{CE}$ 
however, the use of the THEME $^{\circledast}$ program allowed to obtain full T-patterns of the execution of the scheme's tactical corners and outs [15, 17].

In accordance with the results obtained, we found that the observed team achieved in goals few finishing situations resulting from tactical schemes - outs and corners. Studies suggested a higher percentage of goals through tactical schemes $[6,10,13,14]$. However, these studies did not differentiate goals obtained between the various types of tactical schemes (corners, free, penalties, outsides). Several authors mention that the tactical schemes are of special importance in the game of futsal since they allow, through combined plays, to surprise the opponent, enabling advantageous situations of finalization [13, 41].

In a study conducted on the U-20 World Cup, Göral [42] verified that the winning teams got more finishes through corner kicks. Abdel-Hakim [12], in the World Championships Thailand 2012, observed that there were no significant differences between the winning and losing teams in terms of goals obtained through corners. Contrary to our findings, Alves and Bueno [6] reported that in futsal teams of U-17, the highest number of goals were achieved through corners as compared with outsides. In fact, the important thing to note is that tactical schemes are important offensive actions for achieving the goal, and should be explored by teams [41], which implies on the part of the coach the need to devote special attention to this specific game aspect when planning the training [14].

Álvarez Medina et al. [43], in an observational study on the goals scored in 2 seasons of the Spanish Professional Futsal League, noted that goal finishes were the result of rapid movements, with one or two passes, involving 1 or 2 players. The results of our notational analysis remain in line with this finding. We verified that the finishes occurred preferably after a pass, where 2 players were involved. The T-patterns recorded by us also show that the team observed in the marking of the tactical schemes takes advantage of the fast moves of the players to create conditions to finish immediately after the first pass. This is true in the marking of corners and outsides.

Another aspect that emerges from the notational and T-patterns analysis is that owing to the defensive concentration of the opposing team in the areas close to their goal, the tactical schemes are marked preferably for exterior zones 5, 8, and 9, where the largest number of finishes occur. It should be noted that through the analysis of T-patterns, it is possible to check in the marking of the outsides the use of the short pass for a player to end in an area near the location of the marking of the tactical scheme, and the use of the long pass to which the finalization comes from the side opposite the marking location of the outside (zones 5 and 8). From the same analysis we concluded the occurrence of a delayed pass so that the finalization emerged from zone 9. Lapresa et al. [16], also through the analysis of T-patterns in a team in the European Championships of 2010, observed a tactical scheme (out) in which the finalization pass appeared delayed to outer zone 9. In our study, it was still possible to check, in the corners, a pattern of tactical scheme in which the final pass came back, however, to interior zone 7 .

In the sequential analysis carried out, although it was not possible to register standard full sequences, we noted some regularities, notably in the execution of the second pass for later finalization. We also verified regularities in the finalization in interior zone 2 , a fact that is mirrored in the notational analysis, especially in the tactical scheme corners. Abdel-Hakim [12], in a study where he analysed the goals scored in the World Cup of Thailand 2012, found that the highest percentage of goals resulted from finalities in the penalty area. In our investigation, most of the finishes occurred in the outer areas, owing to the great defensive concentration of the adversary, which can explain the low efficiency recorded by the observed team. The notational analysis reported that the goals of the opposing team were intercepted, went out by the final line, or were defended by the goalkeeper.

In terms of practical application, this study gives the coaches 3 complementary forms of analysis of the tactical schemes, and it has been possible to detect patterns in the execution of the balls stopped in an elite futsal team. The observation and analysis have relevance in examining the team's own performance, as well as in the strategic preparation of the next game with the knowledge of the opponent [44]. The 3 techniques used for game analysis were applied in studies of the offensive process $[8,16]$, of the way the teams obtained the goals [17], and of the action of goalkeepers [45].

Future studies within the observation and analysis of the tactical schemes in futsal, using the technique of analysis of polar coordinates [46], should investigate more league teams, differentiated competitive contexts, women's futsal.

Studies involving observation and analysis are an important contribution to greater knowledge of the game, providing significant information to trainers and researchers. The relevance of this study also consists in providing coaches with analysis techniques which can be used in examining different moments 
A. Ferreira, R. Santos, H. Louro, P. M. Sousa, V. Pinheiro, F. Santos, Tactical scheme analysis in futsal

of the game, allowing the investigation of their own and the opposing team, and supporting the training process and strategic planning of a competition.

\section{Conclusions}

We found that owing to the strong defensive concentration of the adversary, the observed team performed movements to free players in areas of external finalization, and these happened preferably after the realization of a pass. We also recorded some regularities in situations where the tactical schemes were finalized through 2 passes.

\section{Disclosure statement}

No author has any financial interest or received any financial benefit from this research.

\section{Conflict of interest}

The authors state no conflict of interest.

\section{References}

1. Agras H, Ferragut C, Abraldes A. Match analysis in futsal: a systematic review. Int J Perform Anal Sport. 2016; 16(2):652-686; doi: 10.1080/24748668.2016.11868915.

2. Sarmento H, Bradley P, Travassos B. The transition from match analysis to intervention: optimising the coaching process in elite futsal. Int J Perform Anal Sport. 2015; 15(2):471-488; doi: 10.1080/24748668.2015.118668807.

3. Gonzalez-Rodenas J, Lopez-Bondia I, Calabuig F, PérezTurpin JA, Aranda R. Creation of goal scoring opportunities by means of different types of offensive actions in US major league soccer. Hum Mov. 2017;18(5):106-116; doi: 10.5114/hm.2017.73616.

4. Correia V, Araújo D, Duarte R, Travassos B, Passos P, Davids K. Changes in practice task constraints shape decision-making behaviours of team games players. J Sci Med Sport. 2012;15(3):244-249; doi: 10.1016/j. jsams.2011.10.004.

5. Pádua PHC, Pádua FLC, Pereira M, Sousa MTD, Oliveira $\mathrm{MB}$, Wanner EF. A vision-based system to support tactical and physical analyses in futsal. Mach Vis Appl. 2017;28(5-6):475-496; doi: 10.1007/s00138-017-0849-z.

6. Alves IP, Bueno L. Analysis of goals in the first phase of the futsal league 2012 [in Portuguese]. Rev Bras Futsal Futebol. 2012;4(12):118-123.

7. Wolański P, Muracki J, Goliński D, Nosal J, BakońskaPacoń E, Murawska-Ciałowicz E. The intensity and energy expenditure of exertions, restitution speed, and rate of perceived exertion after tournament matches in Polish futsal players. Hum Mov. 2017;18(1):58-66; doi: 10.1515/humo-2017-0008.

8. Sarmento H, Bradley P, Anguera MT, Polido T, Resende R, Campaniço J. Quantifying the offensive sequences that result in goals in elite futsal matches. $\mathrm{J}$
Sports Sci. 2016;34(7):621-629; doi: 10.1080/02640414. 2015.1066024.

9. Moura FA, Santana JE, Marche AL, Aguiar TH, Rodrigues AC, Barros RML, et al. Quantitative analysis of futsal players' organization on the court. Port J Sport Sci. 2011;11(Suppl. 2):105-108.

10. Fukuda JPS, Santana WC. Analysis of goals in the futsal league 2011 [in Portuguese]. Rev Bras Futsal Futebol. 2012;4(11):62-66.

11. Lapresa D, Camerino O, Cabedo J, Anguera MT, Jonsson GK, Arana J. Degradation of T-patterns in observational studies: a study on the effectiveness in futsal [in Spanish]. Cuad Psicol Deporte. 2015;15(1):71-82; doi: 10.4321/S1578-84232015000100007.

12. Abdel-Hakim HH. Quantitative analysis of performance indicators of goals scored in the futsal World Cup Thailand 2012. Pamukkale J Sport Sci. 2014;5(1):113-127.

13. Santos MAB, Navarro AC. Analysis of the FIFA Futsal 2008 World Cup goals [in Portuguese]. Rev Bras Futsal Futebol. 2010;2(4):33-36.

14. Giani G, Soares GF, Silva SA. Analysis of the technical and tactical parameters of the goals in the Spanish Futsal League 2015/2016 [in Portuguese]. Rev Bras Futsal Futebol. 2018;10(36):69-76.

15. Lapresa D, Arana J, Anguera MT, Garzón B. Comparative analysis of sequentiality using SDIS-GSEQ and THEME: a concrete example in soccer. J Sports Sci. 2013; 31(15):1687-1695;doi:10.1080/02640414.2013.796061.

16. Lapresa D, Álvarez L, Arana J, Garzón B, Caballero V. Observational analysis of the offensive sequences that ended in a shot by the winning team of the 2010 UEFA Futsal Championship. J Sports Sci. 2013;31(15):17311739; doi: 10.1080/02640414.2013.803584.

17. Santos FJL, Sarmento H, Mendes B, Mauricio N, Furtado B, Sousa PM, et al. Complementary analysis of goals in soccer through notational analysis, sequential analysis, and detection of T-patterns [in Portuguese]. Rev Bras Futsal Futebol. 2017;9(34):238-249.

18. Travassos B, Bourbousson J, Esteves PT, Marcelino R, Pacheco M, Davids K. Adaptive behaviours of attacking futsal teams to opposition defensive formations. Hum Mov Sci. 2016;47:98-105; doi: 10.1016/j.humov.2016. 02.004 .

19. Anguera MT, Hernández Mendo A. Observational methodology in sport sciences [in Spanish]. Rev Cienc Deporte. 2013;9(3):135-160.

20. Anguera MT, Hernández-Mendo A. Observational methodology and sports psychology: state of affairs [in Spanish]. Rev Psicol Deporte. 2014;23(1):103-109.

21. Chacón-Moscoso S, Sanduvete-Chaves S, Anguera MT, Losada JL, Portell M, Lozano-Lozano JA. Preliminary checklist for reporting observational studies in sports areas: content validity. Front Psychol. 2018;9:291; doi: 10.3389/fpsyg.2018.00291.

22. Portell M, Anguera MT, Hernández-Mendo A, Jonsson GK. Quantifying biopsychosocial aspects in everyday contexts: an integrative methodological approach 
from the behavioral sciences. Psychol Res Behav Manag. 2015;8:153-160; doi: 10.2147/PRBM.S82417.

23. Anguera MT, Blanco-Villaseñor A, Losada JL, Portell M. Guidelines for designing and conducting a study that applies observational methodology [in Spanish]. An Psicol.2018;48(1):9-17; doi:10.1016/j.anpsic.2018.02.001.

24. Suárez MC, Rabaz FC, Fernández-Echeverría C, González-Silva J, Moreno Arroyo MP. Design and validation of an observation instrument to assess decision making in the reception action of volleyball [in Spanish]. Cult Cienc Deporte. 2017;12(34):67-75; doi: 10.12800/ ccd.v12i34.833.

25. Blanco-Villaseñor A, Castellano J, Hernández-Mendo A, Sánchez-López CR, Usabiaga O. Application of the generalizability theory in sport to study the validity, reliability and estimation of samples [in Spanish]. Rev Psicol Deporte. 2014;23(1):131-137.

26. Brewer CJ, Jones RL. A five-stage process for establishing contextually valid systematic observation instruments: the case of Rugby Union. Sport Psychol. 2002; 16(2):138-159; doi: 10.1123/tsp.16.2.138.

27. Cohen J. A coefficient of agreement for nominal scales. Educ Psychol Meas. 1960;20(1):37-46; doi: 10.1177/ 001316446002000104.

28. Hernández-Mendo A, Castellano J, Camerino O, Jonsson G, Blanco-Villaseñor A, Lopes A, Anguera MT. Observational software, data quality control and data analysis [in Spanish]. Rev Psicol Deporte. 2014;23(1): 111-121.

29. Gabin B, Camerino O, Anguera MT, Castañer M. Lince: multiplatform sport analysis software. Procedia Soc Behav Sci. 2012;46:4692-4694; doi: 10.1016/j. sbspro.2012.06.320.

30. Bakeman R, Quera V. Sequential analysis and observational methods for the behavioral sciences. Cambridge: Cambridge University Press; 2011.

31. Magnusson MS. Discovering hidden time patterns in behavior: T-patterns and their detection. Behav Res Methods Instrum Comput. 2000;32(1):93-110; doi: 10.3758/BF03200792.

32. Castellano Paulis J, Hernández-Mendo A. Sequential analysis in soccer [in Spanish]. Psicothema. 2000; 12(Suppl. 2):117-121.

33. Castelão DP, Garganta J, Afonso J, Costa IT. Sequential analysis of attacking behaviors performed by toplevel national soccer teams [in Portuguese]. Rev Bras Cienc Esporte. 2015;37(3):230-236; doi: 10.1016/j. rcbe.2015.05.001.

34. Garcia-Fariña A, Jiménez-Jiménez F, Anguera MT. Observation of communication by physical education teachers: detecting patterns in verbal behavior. Front Psychol. 2018;9:334; doi: 10.3389/fpsyg.2018.00334.

35. Sarmento H, Anguera MT, Pereira A, Campaniço J, Leitão J. Patterns of play in the fast attack of F. C. Barcelona, Manchester United and Internazionale Milano - a mixed method approach [in Spanish]. Cuad Psicol Deporte. 2016;16(1):31-42.
36. Soto-Valero C, Bourcier J, Baudry B. Detection and analysis of behavioral T-patterns in debugging activities. Proceedings of the $15^{\text {th }}$ International Conference on Mining Software Repositories, Gothenburg, Sweden, May 28-29,2018;110-113; doi:10.1145/3196398.3196452.

37. Casarrubea M, Jonsson GK, Faulisi F, Sorbera F, Di Giovanni G, Benigno A, et al. T-pattern analysis for the study of temporal structure of animal and human behavior: a comprehensive review. J Neurosci Methods. 2015;239:34-46; doi: 10.1016/j.jneumeth.2014.09.024.

38. Hughes M, James N. Notational analysis of soccer. In: Milanovic D, Prot F (eds.), Proceedings book of the $5^{\text {th }}$ International Scientific Conference on Kinesiology, Zagreb. Zagreb: Faculty ok Kinesiology, University of Zagreb; 2008; 644-660.

39. Nevill AM, Atkinson G, Hughes MD, Cooper SM. Statistical methods for analysing discrete and categorical data recorded in performance analysis. J Sports Sci. 2002;20(10):829-844; doi: 10.1080/0264041023206 75666.

40. Clemente FM, Martins FML, Mendes RS. Analysis of scored and conceded goals by a football team throughout a season: a network analysis. Kinesiology. 2016;48(1): 103-114.

41. Leite WSS. Analysis of the offensive process of the Portuguese futsal team. Pamukkale J Sport Sci. 2012;3(3): 78-89.

42. Göral K. FIFA U-20 World Cup 2013: analysis and evaluation of goals scored. Rev Bras Futsal Futebol. 2016; 8(28):29-38.

43. Álvarez Medina J, Murillo Lorente V, García Felipe A, Parra Artal A. Observational analysis of the goals in the two seasons of the Spanish professional futsal league [in Spanish]. Rev Int Med Cienc Act Fis Deporte. 2018; 18(69):27-42; doi: 10.15366/rimcafd2018.69.002.

44. Martin D, Swanton A, Bradley J, McGrath D. The use, integration and perceived value of performance analysis to professional and amateur Irish coaches. Int J Sports Sci Coach. 2018;13(4):520-532; doi: 10.1177/ 1747954117753806.

45. Lapresa AD, Chivite NJ, Arana IJ, Anguera MT, Barbero CJR. Analysis of the effectiveness of under-16 football goalkeepers. Apunts Educ Fis Esports. 2018;131: 60-79; doi: 10.5672/apunts.2014-0983.es.(2018/1). 131.05 .

46. Maneiro R, Amatria M, Moral JE, López S. Observational analysis of the interline relationships of the Spanish soccer team, using polar coordinates [in Spanish]. Cuad Psicol Deporte. 2018;18(2):18-32. 